\title{
Growth of cucumber seedlings in different varieties as affected by light environment
}

\author{
Fang $\mathrm{Ji}^{{ }^{*}}$, Siqi Wei ${ }^{1}$, Nan $\mathrm{Liu}^{1}$, Lijun $\mathrm{Xu}^{1}$, Po Yang ${ }^{2}$ \\ (1. Key Laboratory of Agricultural Engineering in Structure and Environment of Ministry of Agriculture and Rural Affairs, \\ College of Water Resources \& Civil Engineering, China Agricultural University, Beijing 100083, China; \\ 2. Beijing Lighting Valley Technology Company, Beijing 100083, China)
}

\begin{abstract}
High-quality cucumber seedlings are a prerequisite for ensuring high yield of cucumbers. With the continuous increase of cucumber planting area in China, the demand for high-quality cucumber seedlings is also increasing. One of the important ways to improve the quality of cucumber seedlings is to improve the light environment by using artificial light source. In this study, three cucumber seedlings (cv. Jintong, cv. Yunv and cv. Xiazhiguang) were grown for $23 \mathrm{~d}$ under eight levels of daily light integral (DLI) at $4.3 \mathrm{~mol} /\left(\mathrm{m}^{2} \cdot \mathrm{d}\right), 8.6 \mathrm{~mol} /\left(\mathrm{m}^{2} \cdot \mathrm{d}\right), 10.1 \mathrm{~mol} /\left(\mathrm{m}^{2} \cdot \mathrm{d}\right), 13.0 \mathrm{~mol} /\left(\mathrm{m}^{2} \cdot \mathrm{d}\right), 5.8 \mathrm{~mol} /\left(\mathrm{m}^{2} \cdot \mathrm{d}\right), 11.5 \mathrm{~mol} /\left(\mathrm{m}^{2} \cdot \mathrm{d}\right)$, $14.4 \mathrm{~mol} /\left(\mathrm{m}^{2} \cdot \mathrm{d}\right)$ and $17.3 \mathrm{~mol} /\left(\mathrm{m}^{2} \cdot \mathrm{d}\right)$, respectively. The results showed that when DLI was $14.4 \mathrm{~mol} /\left(\mathrm{m}^{2} \cdot \mathrm{d}\right)$, the seedling height, stem diameter, total leaf area and shoot dry/fresh weight of all three cucumber cultivars reached the maximum, while hypocotyl length decreased with the increase of light intensity. When DLI was $14.4 \mathrm{~mol} /\left(\mathrm{m}^{2} \cdot \mathrm{d}\right)$, Jintong and Xiazhiguang had the highest health index, which were 49.29 and 28.56, respectively, while that of Yunv was 81.59 (DLI $=14.4 \mathrm{~mol} /\left(\mathrm{m}^{2} \cdot \mathrm{d}\right)$ ). With the increase of DLI, the photosynthetic capacity of cucumber increases gradually. The highest net photosynthetic rate was shown at DLI of $14.4 \mathrm{~mol} /\left(\mathrm{m}^{2} \cdot \mathrm{d}\right)$, while the chlorophyll content of cucumber seedlings of all three cultivars were less affected by DLI. Jintong and Yunv had the highest chlorophyll content when DLI was $8.6 \mathrm{~mol} /\left(\mathrm{m}^{2} \cdot \mathrm{d}\right)$ because they were adapted to low-light environment. In conclusion, the DLI of $14.4 \mathrm{~mol} /\left(\mathrm{m}^{2} \cdot \mathrm{d}\right)$ for Jintong and Xiazhiguang, while that of $17.3 \mathrm{~mol} /\left(\mathrm{m}^{2} \cdot \mathrm{d}\right)$ for Yunv are suggested for the light environment design of factory-cultivated seedling for cucumber.
\end{abstract}

Keywords: cucumber seedling, daily light integral (DLI), growth, photosynthesis

DOI: $10.25165 /$ j.ijabe.20201305.5566

Citation: Ji F, Wei S Q, Liu N, Xu L J, Yang P. Growth of cucumber seedlings in different varieties as affected by light environment. Int J Agric \& Biol Eng, 2020; 13(5): 73-78.

\section{Introduction}

Cucumber, as an important economic crop, is one of the main vegetables widely planted in the world. It has the status of second only to tomato in fruit vegetables. Because of its rich taste and nutritional value, cucumber is deeply loved by consumers and plays an increasingly important role in agricultural structure adjustment and farmers' income increase. China is the largest cucumber producing country in the world in terms of scale and yield. In 2018, the cucumber cultivation area in China was 1.05 million $\mathrm{hm}^{2}$, accounting for half of the world's cucumber cultivation area, and the annual yield was about 56.29 million $\mathrm{t}^{[1]}$.

With the increasing market demand of cucumber, the planting area of cucumber is gradually expanding, and the off-season planting of cucumber in solar greenhouse has been vigorously promoted. However, there is an obvious gap in cucumber yield per unit area in China, with the high yield reaching more than

Received date: $2020-03-24 \quad$ Accepted date: $2020-08-12$

Biographies: Siqi Wei, Undergraduate, research interest: plant environmental physiology, Email: 384486545@qq.com; Nan Liu, Master, research interest: plant environmental physiology, Email: 460292508@qq.com; Lijun Xu, Master, research interest: plant environmental physiology, Email: 1048765506@qq.com; Po Yang, Master, Engineer, research interest: plant factory technology, Email: 199620825@qq.com.

*Corresponding author: Fang $\mathbf{J i}, \mathrm{PhD}$, Lecturer, research interest: plant environmental physiology. Key Lab. Agricultural Engineering in Structure and Environment of Ministry of Agriculture and Rural Affairs, College of Water Resources \& Civil Engineering, China Agricultural University, Beijing 100083, China. Tel: +86-10-62737550, Email: jifang@ cau.edu.cn.
$150000 \mathrm{~kg} / \mathrm{hm}^{2}$ and the low yield only reaching $56000 \mathrm{~kg} / \mathrm{hm}^{2[2]}$. The quality of cucumber seedlings plays an important role in the yield and quality of cucumber fruits. Therefore, in order to ensure the stable production of high-quality cucumbers, high-quality seedlings should be determined first ${ }^{[3]}$. The annual demand for cucumber seedlings in China is 47 billion, thus, high-quality seedlings are of great significance for farmers to increase production and income. However, the growth and development of cucumber seedling have been affected by the lack of light caused by the seasonal adverse climate conditions in winter and early spring, which could affect the quality and yield of cucumber and reduce economic benefits.

Light is an important environmental factor affecting the growth and development of plants, not only as of the only energy source of photosynthesis but also as an external signal ${ }^{[4]}$. Light imposes a wide range of regulatory effects on plants, particularly on their morphological variations, various physiological processes and growth and quality of the final products ${ }^{[5,6]}$. Thus, suitable light environment can ensure the quality of seedling, which is conducive to optimize the effect in later cultivation and improve the overall benefit of vegetable production.

Light intensity and photoperiod are two important environmental factors affecting plant growth. Light intensity plays an important role in plant growth and development by affecting photosynthesis. In the process of growth, plant morphological, physiological and biochemical, as well as quality and yield are affected by light intensity. In the specific growth stage of plants, too low light or too high light is both adverse environmental factors. Low light intensity cannot meet the 
requirements of photosynthetic capacity, resulting in the lack of assimilation synthesis, which seriously affects the growth, development and yield of vegetables. On the contrary, the too high light intensity may lead to a significant decrease in the photochemical activity of photosystem II or photosystem I, resulting in photoinhibition ${ }^{[7]}$. The leaf number, plant height, chlorophyll content, net photosynthetic rate, fresh weight and dry weight of seedlings and vegetables decreased with the decrease of light intensity ${ }^{[8]}$. The results of Jang et al. ${ }^{[9]}$ showed that with the increase of photosynthetic photon flux (PPF), hypocotyl diameter, leaf area and dry weight of cucumber seedlings increased, but hypocotyl length, root shoot ratio and specific leaf area decreased, higher PPF treatment can improve the growth and quality of cucumber grafted seedlings. Photoperiod mainly affects biomass accumulation, flower bud differentiation and metabolite formation by transforming the time of photosynthesis. An appropriate increase of photoperiod is conducive to plant height and leaf development, which can promote seedling growth ${ }^{[10]}$. Hurd ${ }^{[11]}$ found that the dry weight of the tomato seedling at long day was almost twice of the short days, and the leaf area increased by $55 \%$, the net assimilation rate, relative growth rate and relative leaf area growth rate of long-term were all larger, but the growth difference decreased with time. The research of Craufurd and Cartwright ${ }^{[12]}$ exhibited that on the apical development of spring wheat, the shorter the photoperiod, the slower the development of the root tip.

Although light intensity and photoperiod are important factors affecting plant growth and development, they cannot independently reflect the response of plants to light. The daily light integral (DLI), the total amount of light received by plants in a day, could use to reflect the response of plants to light ${ }^{[13]}$, which provides a more perfect parameter for exploring the response mechanism of plants to light. The calculation formula of DLI is DLI=Light intensity $\times$ Photoperiod $\times 3600 / 10^{6}$. In the commercial production, DLI can be improved by supplementing light, so as to improve the quality of seedlings. Therefore, DLI can be used for yield prediction or management strategy adjustment in plant production system ${ }^{[14]}$. Hernández and Kubota ${ }^{[15]}$ showed that the number of leaves and dry weight of cucumber increased significantly with the increase of DLI. The response of different plants to DLI was also different, the suitable DLI for tomato seedling growth was $4.8-6.0 \mathrm{~mol} /\left(\mathrm{m}^{2} \cdot \mathrm{d}\right)^{[16]}$, and for purple leaf lettuce was $11.5 \mathrm{~mol} /\left(\mathrm{m}^{2} \cdot \mathrm{d}\right)^{[17]}$.

Compared with the traditional way of seedling raising, the factory seedling has the advantages of scientific environment control, automatic irrigation, uniform growth and high quality of seedling ${ }^{[18]}$, which could improve the production efficiency and reduce the adverse effects of objective factors such as weather. Thus, it is widely used in the seedling production of vegetables. In this study, a plant factory was used to change the light intensity and photoperiod to optimize the DLI, combined with the analysis of the photosynthetic capacity of cucumber seedlings, to study the light environment parameters suitable for cucumber seedling, and to provide a theoretical basis for its industrialized seedling.

\section{Materials and methods}

\subsection{Plant materials and growth conditions}

The seeds of three cultivars of cucumber (Cucumis sativus L.) (cv. Jintong, cv. Yunv and cv. Xiazhiguang) provided by Rijk Zwaan (China) Seed Co., Ltd. The dark-green Jintong and the light-white-green Yunv are both early maturing cultivars, which are oval, smooth, spineless and $4-5 \mathrm{~cm}$ in length, with an average weight of single melon $30 \mathrm{~g}$. Xiazhiguang is an early maturing cultivar, which is emerald green, smooth and $16-18 \mathrm{~cm}$ in length long, with an average weight of single melon 80-100 g.

This experiment was carried out in the plant factory with artificial light source. A 72-hole tray $(540 \mathrm{~mm} \times 280 \mathrm{~mm})$ was used, and the substrate was a mixture of vermiculite, peat and perlite $(3 \mathrm{~V}: 1 \mathrm{~V}: 1 \mathrm{~V})$. The seeds of cucumber were seeded in a tray filled with mixed substrate and moistened with newspaper. Before seed sprouting, the environment of plant factory was set as follows: temperature in light period $(28 \pm 1)^{\circ} \mathrm{C}$, the temperature in the dark period $(22 \pm 1)^{\circ} \mathrm{C}$, relative humidity $80 \% \pm 10 \%$, uncontrolled $\mathrm{CO}_{2}$ concentration and without light. After sprouting, the light was turned on according to the light environment parameters set in each treatment, with the seedling environment set as follows: temperature $(24 \pm 1)^{\circ} \mathrm{C}$, relative humidity $70 \% \pm 5 \%$ and $\mathrm{CO}_{2}$ concentration $400 \pm 50 \mu \mathrm{mol} / \mathrm{mol}$ in light period; temperature $(20 \pm 1)^{\circ} \mathrm{C}$, relative humidity $80 \% \pm 10 \%$ and uncontrolled $\mathrm{CO}_{2}$ concentration in dark period. The Japanese horticultural experimental nutrient formula was used (Table 1), and the nutrient solution was irrigated by bottom irrigation. During the period from seed budding to the first true leaf unfolded, the nutrient solution of $1 / 2$ concentration was irrigated every two days; after the first true leaf unfolded, the nutrient solution of standard concentration was irrigated (pH: 6.8-7.2, EC: $2.0-2.4 \mathrm{mS} / \mathrm{cm}$ ), and the duration of substrate absorbing nutrient solution during bottom irrigation was $30 \mathrm{~min}$.

Table 1 Japanese horticultural experimental nutrient formula for seedling

\begin{tabular}{lcc||cc}
\hline \multicolumn{1}{c}{ Major element } & Molar concentration $/ \mathrm{mmol} \cdot \mathrm{L}^{-1}$ & Mass concentration $/ \mathrm{mg} \cdot \mathrm{L}^{-1}$ & \multicolumn{1}{c}{ Trace element } & Mass concentration $/ \mathrm{mg} \cdot \mathrm{L}^{-1}$ \\
\hline $\mathrm{KNO}_{3}$ & 8 & 808 & DTPA-Fe $(7 \%)$ & 42.86 \\
$\mathrm{Ca}\left(\mathrm{NO}_{3}\right)_{2} \cdot 4 \mathrm{H}_{2} \mathrm{O}$ & 4 & 944 & $\mathrm{CuSO}_{4} \cdot 5 \mathrm{H}_{2} \mathrm{O}$ & 0.08 \\
$\mathrm{MgSO}_{4} \cdot 7 \mathrm{H}_{2} \mathrm{O}$ & 2 & 492 & $\mathrm{MnSO}_{4} \cdot \mathrm{H}_{2} \mathrm{O}$ & 1.54 \\
$\mathrm{NH}_{4} \mathrm{H}_{2} \mathrm{PO}_{4}$ & 1.33 & 153 & $\mathrm{ZnSO}_{4} \cdot 7 \mathrm{H}_{2} \mathrm{O}$ & 0.22 \\
& & & $\mathrm{H}_{3} \mathrm{BO}_{3}$ & 2.82 \\
& & & $\left(\mathrm{NH}_{4}\right)_{6} \mathrm{Mo}_{7} \mathrm{O}_{24} \cdot 4 \mathrm{H}_{2} \mathrm{O}$ & 0.03 \\
\hline
\end{tabular}

\subsection{Treatment design}

Four four-layer seedling stands (L1300 $\mathrm{mm} \times \mathrm{W} 900 \mathrm{~mm} \times$ $\mathrm{H} 2100 \mathrm{~mm}$, layer height $400 \mathrm{~mm}$ ) were used in this experiment. Six trays were placed in each layer, and three trays were planted for each cultivar of cucumber in different treatments. T5 fluorescent lamp (28 W, Shanghai Flower and Biology Lighting Co., Ltd., China) was used as artificial light source, and the light intensity of the cultivation surface was regulated by controlling the number of lights.

Four light intensities $\left(100,200,250\right.$ and $\left.300 \mu \mathrm{mol} /\left(\mathrm{m}^{2} \cdot \mathrm{s}\right)\right)$ and two photoperiods $(12 \mathrm{~h} / \mathrm{d}$ and $16 \mathrm{~h} / \mathrm{d})$ were designed in this experiment (Table 2). The light intensity is measured at $15 \mathrm{~cm}$ directly below the lamp by a portable light quantum meter (LI-1400, LI-COR Inc., USA). The light on time corresponding to $12 \mathrm{~h} / \mathrm{d}$ 
and $16 \mathrm{~h} / \mathrm{d}$ photoperiod were 08:00-20:00 and 08:00-00:00, respectively.

Table 2 Light environment setting with light intensity and photoperiod

\begin{tabular}{cccc}
\hline Treatment & $\begin{array}{c}\text { Photosynthetic } \\
\text { photon flux density } \\
/ \mu \mathrm{mol} \cdot \mathrm{m}^{-2} \cdot \mathrm{s}^{-1}\end{array}$ & $\begin{array}{c}\text { Photoperiod } \\
/ \mathrm{h} \cdot \mathrm{d}^{-1}\end{array}$ & $\begin{array}{c}\text { Daily light } \\
\text { integral (DLI) } \\
/ \mathrm{mol}^{-2} \cdot \mathrm{m}^{-2} \cdot \mathrm{d}^{-1}\end{array}$ \\
\hline P100-H12 & 100 & & 4.3 \\
P200-H12 & 200 & 12 & 8.6 \\
P250-H12 & 250 & & 10.1 \\
P300-H12 & 300 & & 13.0 \\
\hline P100-H16 & 100 & 16 & 5.8 \\
P200-H16 & 200 & & 11.5 \\
P250-H16 & 250 & & 14.4 \\
P300-H16 & 300 & & 17.3 \\
\hline
\end{tabular}

\subsection{Growth measurements}

2.3.1 Plant morphology and growth characteristics

Eight seedlings were randomly selected at $23 \mathrm{~d}$ after sowing from each treatment. The morphological measurement included seedling height, stem diameter, hypocotyl length and total leaf area; the biomass of seedlings included shoot and root fresh/dry weight. The fresh weights were measured by an electronic analytical balance (FA1204B, Shanghai Precision Scientific Instruments Co., Ltd., China), and the shoot and root parts of cucumber seedlings were placed in an oven at $105^{\circ} \mathrm{C}$ for $3 \mathrm{~h}$, then the oven temperature was adjusted to $80^{\circ} \mathrm{C}$ and dried for $72 \mathrm{~h}$ to constant weight for measuring the dry weights. The health index was determined using Equation (1):
Health index $=$ Stem diameter $/$ Seedling height $\times$ Dry weight

\subsubsection{Chlorophyll content}

The chlorophyll content was determined by UV/VIS spectrophotometer (UV-3150, Shimadzu Co., Japan). Six fresh leaves of different seedlings were taken from each treatment to measure the chlorophyll content, and Arnon's method ${ }^{[19]}$ was used to calculate the chlorophyll content.

2.3.3 Net photosynthetic rate

The net photosynthetic rates $\left(\mathrm{P}_{\mathrm{n}}, \mu \mathrm{mol} /\left(\mathrm{m}^{2} \cdot \mathrm{s}\right)\right)$ of cucumber seedlings were measured by a portable photosynthesis system (LI-6400XT, LI-COR Inc., America). The parameters of photosynthesis measurement were as follows: air velocity $500 \mu \mathrm{mol} / \mathrm{s}$; light intensity $250 \mu \mathrm{mol} /\left(\mathrm{m}^{2} \cdot \mathrm{s}\right)$; leaf chamber temperature $25^{\circ} \mathrm{C} ; \mathrm{CO}_{2}$ concentration $800 \mu \mathrm{mol} / \mathrm{mol}$.

\subsection{Statistical analysis}

Microsoft Excel 2016 and SPSS 22.0 were used to process and analyze the experimental data. In the process of data statistics, Duncan's method was used to make multiple comparisons at the significance level of 0.05 .

\section{Results and discussion}

\subsection{Effects of light environment on morphology and growth of cucumber seedlings}

Light is the energy source for photosynthetic organisms, light intensity and photoperiod play an important role in plant growth. The morphology of three different kinds of cucumber seedlings was found to be significantly different under different light intensity and photoperiod (Figure 1). With the increase of photoperiod, the seedling height, stem diameter and total leaf area

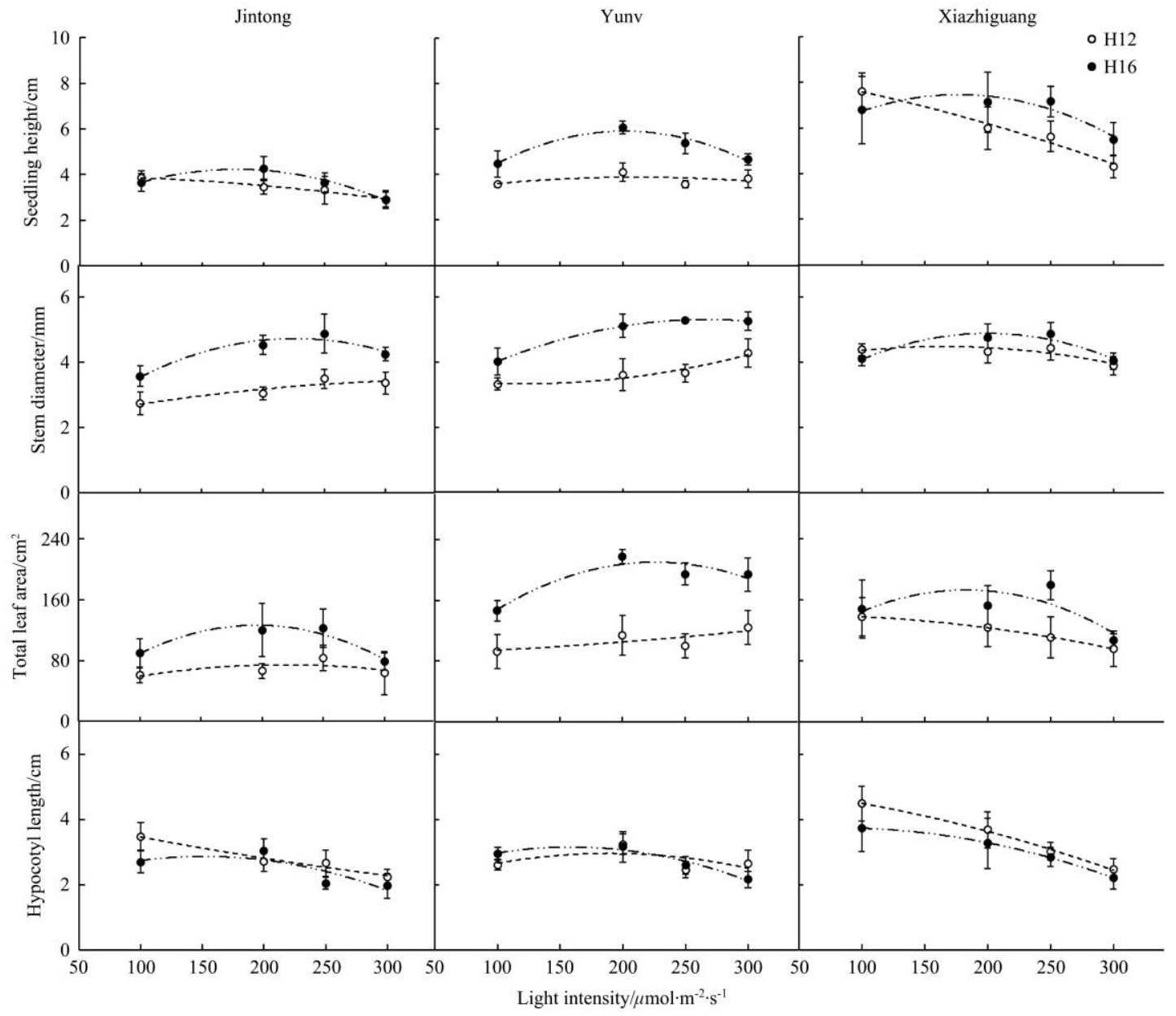

Figure 1 Effects of light intensity and photoperiod on morphology of cucumber seedlings 
of the three cucumber cultivars increased significantly, which is because appropriate increase of photoperiod is helpful to plant growth and leaf development, and also has promoting effect on seedling growth rate ${ }^{[10,20]}$. Photoperiod had no significant effect on hypocotyl length of cucumber seedlings. Light, especially the light intensity, seemed to positively affect plant growth and productivity ${ }^{[21]}$. The morphology of the cucumber seedlings was found to be significantly different under different light intensities. When the photoperiod was $16 \mathrm{~h} / \mathrm{d}$, although the seedling height, stem diameter and leaf area of the three cultivars were different due to different cultivars, they all showed the trend of first increasing and then decreasing with the increase of light intensity, and reached the highest value under $200 \mu \mathrm{mol} /\left(\mathrm{m}^{2} \cdot \mathrm{s}\right)$ or $250 \mu \mathrm{mol} /\left(\mathrm{m}^{2} \cdot \mathrm{s}\right)$. Under $250 \mu \mathrm{mol} /\left(\mathrm{m}^{2} \cdot \mathrm{s}\right)$ and $16 \mathrm{~h} / \mathrm{d}$, the seedling height, stem diameter and total leaf area of Jintong were $3.7 \mathrm{~cm}, 4.9 \mathrm{~mm}$ and $122.8 \mathrm{~cm}^{2}$, respectively; those of Yunv were $5.4 \mathrm{~cm}, 5.3 \mathrm{~mm}$ and $194.7 \mathrm{~cm}^{2}$, respectively; and those of Xiazhiguang were $7.2 \mathrm{~cm}$, $4.9 \mathrm{~mm}$ and $179.6 \mathrm{~cm}^{2}$, respectively. In a certain range, the increase of light intensity is conducive to the formation of plant morphology and the growth of leaves. However, when the light intensity increased, plants will reduce the transpiration of leaves by reducing the leaf area, so as to reduce the damage of excessive light on the photosynthetic system ${ }^{[22]}$. The light intensity has a direct effect on the elongation of hypocotyls of seedlings, and the high light intensity caused cucumber seedlings to have short hypocotyls. In the P300-H16, the hypocotyls of three cucumbers were shortest, which were $1.97 \mathrm{~cm}, 2.17 \mathrm{~cm}$ and $2.20 \mathrm{~cm}$, respectively. Similar findings were reported in the study of Kwack et al. ${ }^{[23]}$

Compared with the photoperiod of $12 \mathrm{~h} / \mathrm{d}$, the shoot fresh/dry weights of the three cucumber cultivars increased significantly under the photoperiod of $16 \mathrm{~h} / \mathrm{d}$. Although the root fresh/dry weights of Jintong and Yunv increased significantly, the root fresh/dry weights of Xiazhiguang did not change significantly (Figure 2), which may be due to the difference of cultivars. The longer photoperiod provides more energy for plants, resulting in more photosynthetic products, and thus promotes the growth of plants ${ }^{[24]}$. Therefore, appropriate extension of photoperiod is conducive to biomass accumulation of cucumber seedlings. Light intensity influences not only the morphology but also the biomass of cucumber seedling. Under $250 \mu \mathrm{mol} /\left(\mathrm{m}^{2} \cdot \mathrm{s}\right)$ and $16 \mathrm{~h} / \mathrm{d}$, the shoot fresh weights of Jintong, Yunv and Xiazhiguang were the highest, which were $4.32 \mathrm{~g}, 7.67 \mathrm{~g}$ and $5.61 \mathrm{~g}$ per plant, respectively. The root fresh weights increased with the increase of light intensity and reached the maximum at $300 \mu \mathrm{mol} /\left(\mathrm{m}^{2} \cdot \mathrm{s}\right)$, which were $1.87 \mathrm{~g}, 2.92 \mathrm{~g}$ and $1.31 \mathrm{~g}$ per plant, respectively. The shoot/root dry weights of the three cucumbers showed the same trend, with the maximum total dry weight of $368.40 \mathrm{mg}, 770.87 \mathrm{mg}$ and $413.47 \mathrm{mg}$ per plant, respectively. Jang et al. ${ }^{[9]}$ also studied the grafted seedlings of cucumber (Cucumis sativus L. cv. Joeun Baekdadaki) and showed that the biomass of seedlings was the highest under $237 \mu \mathrm{mol} /\left(\mathrm{m}^{2} \cdot \mathrm{s}\right)$.

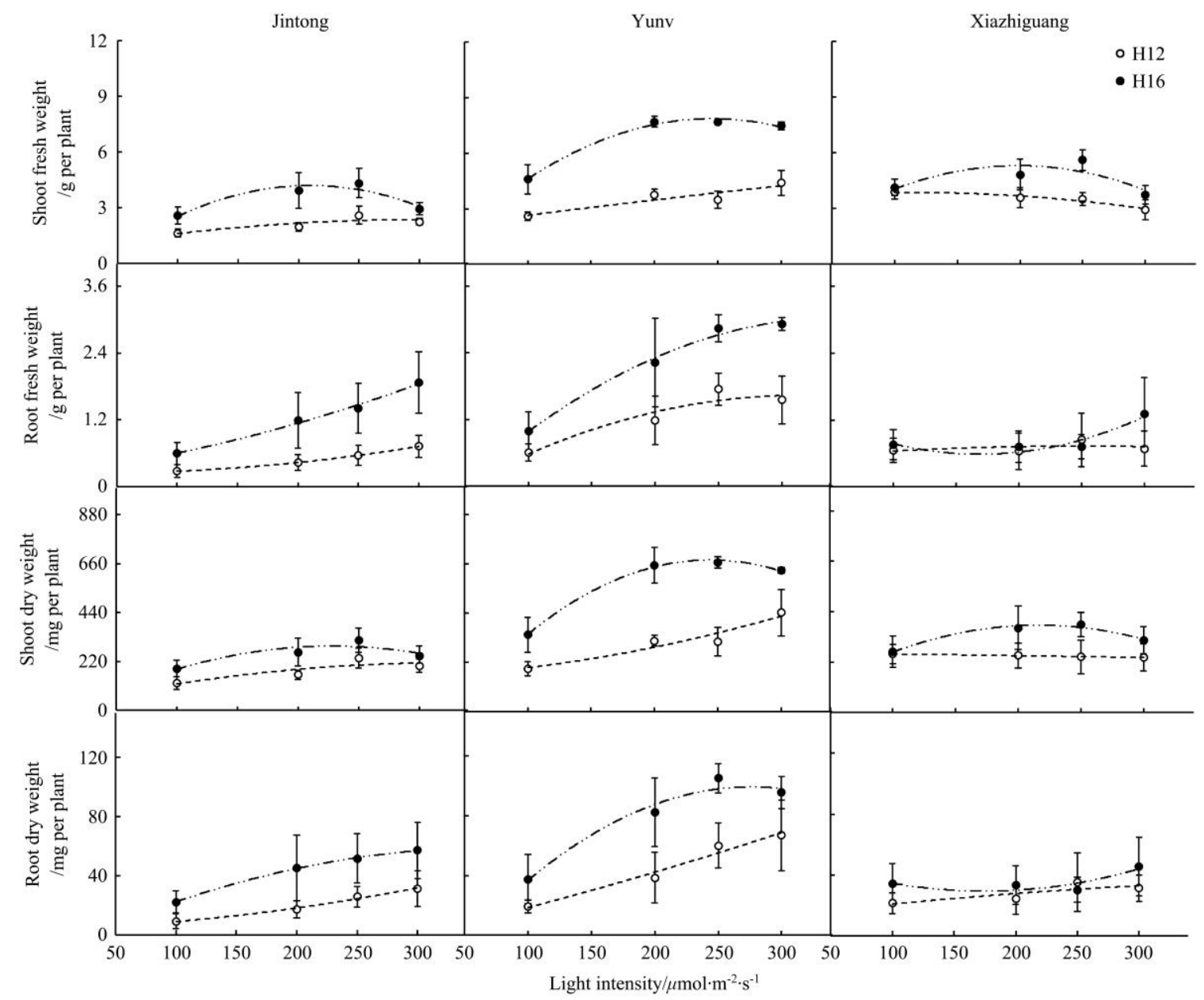

Figure 2 Effects of light intensity and photoperiod on biomass of cucumber seedlings

Morphological is used to measure the quality of seedlings, but it is difficult to comprehensively characterize the quality of seedlings by a single index. Therefore, the composite index of the health index is used to represent the quality of seedlings ${ }^{[25]}$. DLI 
can completely represent the degree and duration of plant photosynthesis and provide more perfect parameters for exploring the response mechanism of plants to light ${ }^{[26]}$. The effect of DLI on the health index of three cucumber cultivars is shown in Figure 3. Under the low DLI, the health index of cucumber seedlings was also low, indicating that low DLI was not suitable for the growth of cucumber seedlings. With the increase of DLI, the health index of Jintong and Xiazhiguang reached the maximum under DLI of $14.4 \mathrm{~mol} /\left(\mathrm{m}^{2} \cdot \mathrm{d}\right)$, which were 49.29 and 28.56 , respectively, $410 \%$ and $78 \%$ higher than that under $4.3 \mathrm{~mol} /\left(\mathrm{m}^{2} \cdot \mathrm{d}\right)$, and began to decrease when DLI was $17.3 \mathrm{~mol} /\left(\mathrm{m}^{2} \cdot \mathrm{d}\right)$. Because of the difference of cultivars, the health index of Yunv (81.59) under DLI of $17.3 \mathrm{~mol} /\left(\mathrm{m}^{2} \cdot \mathrm{d}\right)$ was significantly higher than that of other DLIs, which was $317 \%$ higher than that of $4.3 \mathrm{~mol} /\left(\mathrm{m}^{2} \cdot \mathrm{d}\right)$. Therefore, increasing DLI can accelerate the growth of cucumber seedlings, and beyond a certain range, the promotion of the growth of seedlings to be stable or change to inhibition ${ }^{[22,27]}$. Hao and Papadopoulos $^{[28]}$ also showed that increasing DLI by 9.5$15.9 \mathrm{~mol} /\left(\mathrm{m}^{2} \cdot \mathrm{d}\right)$ could increase cucumber yield, which was similar to our results. As a result, cucumber seedlings have developed sophisticated mechanisms to adapt their structure and physiology to the prevailing light environment. And with the increase of DLI, the stem diameter of cucumber seedlings became thicker, the leaves became larger, the plant type was more compact, and the seedlings were more robust.

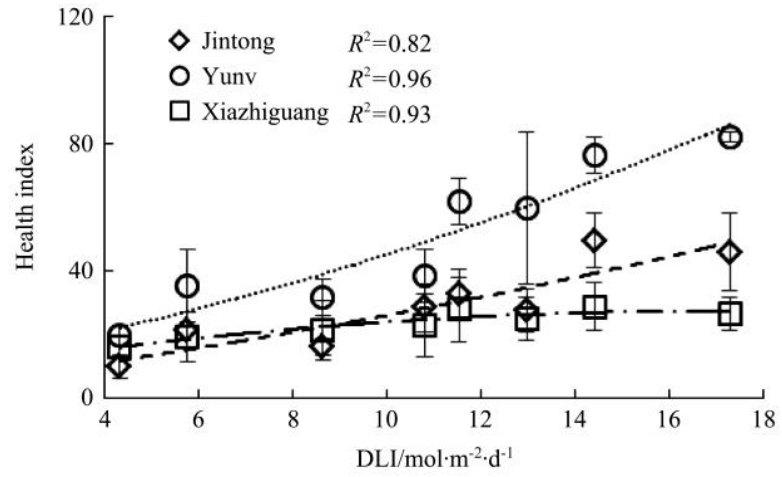

Figure 3 Effect of DLI on health index of cucumber seedlings

\subsection{Effect of DLI on photosynthesis and chlorophyll content} of cucumber seedlings

The effects of DLI on photosynthetic characteristics and total chlorophyll content of cucumber seedlings are shown in Table 3. With the increase of DLI, the net photosynthetic rate of leaves of cucumber seedlings increased, and the photosynthetic capacity of plants increased. Similar results were obtained by Pettersen et al. ${ }^{[29]}$ Under the DLI of $14.4 \mathrm{~mol} /\left(\mathrm{m}^{2} \cdot \mathrm{d}\right)$, the net photosynthetic rate of Jintong reached the maximum, which was 13.27士 $1.35 \mu \mathrm{mol} /\left(\mathrm{m}^{2} \cdot \mathrm{s}\right)$; while the net photosynthetic rate of Yunv was larger under the DLI of $11.5-17.3 \mathrm{~mol} /\left(\mathrm{m}^{2} \cdot \mathrm{d}\right)$, but there was no significant difference. When the DLI was $11.5-14.4 \mathrm{~mol} /\left(\mathrm{m}^{2} \cdot \mathrm{d}\right)$, there was no significant effect on the net photosynthetic rate of Xiazhiguang. When DLI reached $17.3 \mathrm{~mol} /\left(\mathrm{m}^{2} \cdot \mathrm{d}\right)$, the net photosynthetic rate of Jintong and Xiazhiguang began to decrease. This is consistent with the changes in biomass and health index of cucumber seedlings. Biomass production of cucumber seedlings are primarily driven by photosynthesis, which depends on light interception. The health index was positively correlated with plant dry weight, so the enhancement of photosynthetic rate was beneficial to improve the quality of cucumber seedlings.

DLI had little effect on the total chlorophyll content of cucumber seedling leaves. Because of the difference of cultivars, the total chlorophyll content of Jintong and Yunv were the highest under DLI of $8.6 \mathrm{~mol} /\left(\mathrm{m}^{2} \cdot \mathrm{d}\right)$, while that of Xiazhiguang was the highest under DLI of $13.0 \mathrm{~mol} /\left(\mathrm{m}^{2} \cdot \mathrm{d}\right)$. The total chlorophyll content of Jintong and Yunv was the highest under relatively low DLIs, which indicated that the cucumber of these two cultivars adapted to the weak light environment, and the higher chlorophyll content enabled them to absorb more light energy to meet the needs of photosynthesis. The research of Zhang et al. ${ }^{[30]}$ indicated that low light intensity leads to the increase of chlorophyll content, indicating that cucumber leaves regulate these components so that they can obtain limited solar energy as effectively as possible. Liang et al. ${ }^{[31]}$ also reached the same results that under low light, excessive excitation due to the inhibition of photosynthesis can increase the rate of chloroplast production in cucumber seedlings.

Table 3 Effect of DLI on photosynthetic characteristics and total chlorophyll content of cucumber seedlings

\begin{tabular}{|c|c|c|c|c|c|c|}
\hline \multirow{2}{*}{$\begin{array}{c}\text { DLI } \\
/ \mathrm{mol} \cdot \mathrm{m}^{-2} \cdot \mathrm{d}^{-1}\end{array}$} & \multicolumn{2}{|c|}{ Jintong } & \multicolumn{2}{|c|}{ Yunv } & \multicolumn{2}{|c|}{ Xiazhiguang } \\
\hline & $\begin{array}{l}\text { Net photosynthetic rate } \\
\quad / \mu \mathrm{mol} \cdot \mathrm{m}^{-2} \cdot \mathrm{s}^{-1}\end{array}$ & $\begin{array}{l}\text { Total chlorophyll } \\
\text { content } / \mathrm{mg} \cdot \mathrm{g}^{-1}\end{array}$ & $\begin{array}{l}\text { Net photosynthetic rate } \\
\qquad / \mu \mathrm{mol} \cdot \mathrm{m}^{-2} \cdot \mathrm{s}^{-1}\end{array}$ & $\begin{array}{l}\text { Total chlorophyll } \\
\text { content } / \mathrm{mg} \cdot \mathrm{g}^{-1}\end{array}$ & $\begin{array}{l}\text { Net photosynthetic rate } \\
\quad / \mu \mathrm{mol} \cdot \mathrm{m}^{-2} \cdot \mathrm{s}^{-1}\end{array}$ & $\begin{array}{l}\text { Total chlorophyll } \\
\text { content } / \mathrm{mg}^{-1} \mathrm{~g}^{-1}\end{array}$ \\
\hline 4.3 & $7.14 \pm 1.25^{\mathrm{c}}$ & $2.51 \pm 0.07^{\mathrm{ab}}$ & $10.02 \pm 1.08^{\mathrm{d}}$ & $2.25 \pm 0.33^{\mathrm{ab}}$ & $7.56 \pm 1.23^{\mathrm{c}}$ & $1.89 \pm 0.1^{\mathrm{d}}$ \\
\hline 5.8 & $11.72 \pm 1.06^{\mathrm{b}}$ & $2.11 \pm 0.10^{\mathrm{c}}$ & $11.08 \pm 0.5^{\mathrm{bc}}$ & $2.09 \pm 0.15^{\mathrm{b}}$ & $8.23 \pm 0.72^{\mathrm{bc}}$ & $2.32 \pm 0.09^{\mathrm{bc}}$ \\
\hline 8.6 & $10.75 \pm 1.43^{\mathrm{b}}$ & $2.54 \pm 0.11^{\mathrm{a}}$ & $11.45 \pm 1.47 \mathrm{~b}$ & $2.43 \pm 0.30^{\mathrm{a}}$ & $7.44 \pm 1.19^{c}$ & $2.03 \pm 0.32^{\mathrm{c}}$ \\
\hline 11.5 & $10.37 \pm 0.94^{\mathrm{b}}$ & $2.23 \pm 0.17 b^{c}$ & $13.20 \pm 1.03^{\mathrm{ab}}$ & $2.16 \pm 0.21^{\mathrm{b}}$ & $10.72 \pm 1.82^{\mathrm{a}}$ & $2.43 \pm 0.28^{\mathrm{b}}$ \\
\hline 13.0 & $11.68 \pm 1.12^{\mathrm{b}}$ & $2.32 \pm 0.25^{\mathrm{b}}$ & $13.07 \pm 1.05^{\mathrm{ab}}$ & $2.19 \pm 0.30^{\mathrm{b}}$ & $10.24 \pm 1.53^{\mathrm{ab}}$ & $2.82 \pm 0.8^{\mathrm{a}}$ \\
\hline 14.4 & $13.27 \pm 1.35^{\mathrm{a}}$ & $2.49 \pm 0.50^{\mathrm{ab}}$ & $13.33 \pm 1.15^{\mathrm{a}}$ & $2.02 \pm 0.09^{\mathrm{bc}}$ & $10.09 \pm 0.54^{\mathrm{ab}}$ & $2.45 \pm 0.15^{\mathrm{b}}$ \\
\hline 17.3 & $10.95 \pm 1.07^{\mathrm{b}}$ & $2.20 \pm 0.46^{\mathrm{bc}}$ & $12.86 \pm 1.04^{\mathrm{ab}}$ & $1.71 \pm 0.09^{\mathrm{c}}$ & $9.01 \pm 0.76^{\mathrm{b}}$ & $2.54 \pm 0.29^{b}$ \\
\hline
\end{tabular}

Note: Different letters in the same column indicate significant differences $(p<0.05)$ based on Duncan's multiple range test.

\section{Conclusions}

Suitable light environment can promote the growth of cucumber seedlings and ensure their quality, and the influence of light environment on the three cultivars of cucumber is slightly different because of the difference of cultivars. Light intensity and photoperiod have an important impact on the morphogenesis of cucumber seedlings. Under higher photoperiod, an appropriate increase of light intensity can help to promote plant rooting, increase leaf area, increase biomass and shorten hypocotyl length. An appropriate increase in DLI can help increase the photosynthetic capacity of cucumber leaves and improve plant robustness, but too much light can inhibit the growth of cucumber seedlings. In the conclusion, it is suggested that DLI of $14.4 \mathrm{~mol} /\left(\mathrm{m}^{2} \cdot \mathrm{d}\right)$ (light intensity of $250 \mu \mathrm{mol} /\left(\mathrm{m}^{2} \cdot \mathrm{s}\right)$, photoperiod of $16 \mathrm{~h} / \mathrm{d}$ ) should be selected as the light environment conditions for 
Jintong and Xiazhiguang, and the DLI of $17.3 \mathrm{~mol} /\left(\mathrm{m}^{2} \cdot \mathrm{d}\right)$ (light intensity of $300 \mu \mathrm{mol} /\left(\mathrm{m}^{2} \cdot \mathrm{s}\right)$, photoperiod of $\left.16 \mathrm{~h} / \mathrm{d}\right)$ should be selected as the light environment conditions for Yunv.

\section{Acknowledgements}

This work was supported by the National Key Research and Development Program of China (2017YFB0403901).

\section{[References]}

[1] FAOSTAT. 2018. http://www.fao.org/faostat/zh/\#data. Accessed on [2019-01-21].

[2] Xu M, Wang T C, Shun G Z. The key technology of cucumber production per mu in long season of solar greenhouse in suburban Beijing is $25000 \mathrm{~kg}$. Chinese Horticulture Abstracts, 2013; 7: 153-156. (in Chinese)

[3] Liu N, Ji F, Xu L J, He D X. Effects of LED light quality on the growth of pepper seedling in plant factory. Int J Agric \& Biol Eng, 2019; 12(5): 44-50.

[4] Liu W K. Light environmental management for artificial protected horticulture. Agrotechnology, 2012; 1(1): 101-104.

[5] Yan Z N, He D X, Niu G H, Zhou Q, Qu Y H. Growth, nutritional quality, and energy use efficiency in two lettuce cultivars as influenced by white plus red versus red plus blue LEDs. Int J Agric \& Biol Eng, 2020; 13(2): 33-40.

[6] Liu N, Ji F, Xu L J, He D X. Effects of LED light quality on the growth of pepper seedling in plant factory. Int J Agric \& Biol Eng, 2019; 12(5): 44-50.

[7] Yang X Y, Wang X F, Wang L J, Wei M. Control of light environment: A key technique for high-yield and high-quality vegetable production in protected farmland. Agricultural Sciences, 2012; 3(7): 923-928.

[8] Fan X X, Xu Z G, Liu X Y, Tang C M, Wang L W, Han X L. Effects of light intensity on the growth and leaf development of young tomato plants grown under a combination of red and blue light. Scientia Horticulturae, 2013; 153: 50-55.

[9] Jang Y, Goto E, Ishigami Y, Mun B, Chun C. Effects of light intensity and relative humidity on photosynthesis, growth and graft-take of grafted cucumber seedlings during healing and acclimatization. Horticulture Environment and Biotechnology, 2011; 52(4): 331-338.

[10] Adams S R, Langton F A. Photoperiod and plant growth: A review. Journal of Horticultural Science and Biotechnology, 2005; 80 (1): 2-10.

[11] Hurd R G. Long-day effects on growth and flower initiation of tomato plants in low light. Annals of Applied Biology, 1973; 73(2): 221-228.

[12] Craufurd P Q, Cartwright P M. Effect of photoperiod and chlormequat on apical development and growth in a spring wheat (Triticum aestivum) cultivar. Annals of Botany, 1989; 63(5): 515-525.

[13] Brechner M, Albright L, Weston L. Impact of differing light integrals at a constant light intensity: effects on biomass and production of secondary metabolites by Hypericum perforatum. ASABE annual international meeting sponsored by ASABE, Minneapolis, Minnesota, June 17-20, 2007; 074016. doi: 10.13031/2013.24198.

[14] Albright L D, Both A J, Chiu C A. Controlling greenhouse light to a consistent daily integral. Transactions of the ASAE, 2001; 43: 421-431.

[15] Hernández R, Kubota C. Growth and morphological response of cucumber seedlings to supplemental red and blue photon flux ratios under varied solar daily light integrals. Scientia Horticulturae, 2014; 173: 92-99.

[16] Dorais M. The use of supplemental lighting for vegetable crop production: Light intensity, crop response, nutrition, crop management, cultural practices. Canadian Greenhouse Conference. October 9, 2003; pp.1-8.

[17] Yan Z N, He D X, Niu G, Zhai H. Evaluation of growth and quality of hydroponic lettuce at harvest as affected by the light intensity, photoperiod and light quality at seedling stage. Scientia Horticulturae, 2019, 248: 138-144.

[18] Niu G L, Wang G L, Li B B, Song C N, Xiao W W, Zhou H B. Design of rice factory three-dimensional carpet raising seedlings system engineering. IERI Procedia, 2014; 8: 93-100.

[19] Arnon D I. Copper enzymes in isolated chloroplasts: Polyphenoloxidase in Beta vulgaris. Plant Physiology, 1949; 24(1): 1-15

[20] Zhang Y, Wang X R, Chen J. Effects of light quality and photoperiod of light emitting LED on growth and biomass accumulation of shallot. Journal of Horticulture and Forestry, 2019; 11(5): 78-83.

[21] Zavala J A, Ravetta D A. Allocation of photoassimilates to biomass, resin and carbohydrates in Grindelia chiloensis as affected by light intensity. Field Crops Research, 2001; 69(2): 143-149.

[22] Garland K F, Burnett S E, Day M E, van Iersel M W. Influence of substrate water content and daily light integral on photosynthesis, water use efficiency, and morphology of heuchera americana. Journal of the American Society for Horticultural Science, 2012; 137(1): 57-67.

[23] Kwack Y, Kim K K, Hwang H, Chun C. Growth and quality of sprouts of six vegetables cultivated under different light intensity and quality. Horticulture, Environment, and Biotechnology, 2015; 56(4): 437-443.

[24] Hendriks J H M, Kolbe A, Gibon Y, Stitt M, Geigenberger P ADP-glucose pyrophosphorylase is activated by posttranslational redox-modification in response to light and to sugars in leaves of Arabidopsis and other plant species. Plant Physiology, 2003; 133(2): 838-849.

[25] He W, Huang Z W, Li J P, Su W X, Gan L J, Xu Z G. Effect of different light intensities on the photosynthate distribution in cherry tomato seedlings. The Journal of Horticultural Science and Biotechnology, 2019; 94 (5): 611-619.

[26] Faust J E, Heins R D. Modeling leaf development of the African violet (Saintpaulia ionantha Wendl.). Journal of the American Society for Horticultural Science, 1993; 118(6): 747-751.

[27] Wook O, Inhye C, Kisun K, Runkle E S. Photosynthetic daily light integral influences flowering time and crop characteristics of Cyclamen persicum. HortScience, 2009; 44(2): 341-344.

[28] Hao X, Papadopoulos A P. Supplemental lighting in high-wire cucumbers and tomatoes grown on raised gutters. Canadian Greenhouse Conference, Toronto, ON, Canada, 2003.

[29] Pettersen R I, Torre S, Gislerød H R. Effects of intracanopy lighting on photosynthetic characteristics in cucumber. Scientia Horticulturae, 2010; 125(2): 77-81.

[30] Zhang H, Sharifi M R, Nobel P S. Photosynthetic characteristics of sun versus shade plants of Encelia farinosa as affected by photosynthetic photon flux density, intercellular $\mathrm{CO}_{2}$ concentration, leaf water potential, and leaf temperature. Functional Plant Biology, 1995; 22(5): 833-841.

[31] Liang W, Wang $M$, Ai $X$. The role of calcium in regulating photosynthesis and related physiological indexes of cucumber seedlings under low light intensity and suboptimal temperature stress. Scientia Horticulturae, 2009; 123(1): 34-38. 